for $0<j \leqq s$, and $x, y$ arbitrary. Hence, for the same $j$,

$$
\begin{aligned}
& \sum_{p=0}^{2 p \leqq s-1}{ }_{s-1} C_{2 p}(x+4 p+1-s)^{s-j} \\
& \quad+\sum_{p=0}^{2 p \leqq s-2} s-1 C_{2 p+1}(y+4 p+3-s)^{s-} \\
& =\sum_{p=0}^{2 p \leqq s-2}{ }_{s-1} C_{2 p+1}(x+4 p+3-s)^{s-1} \\
& \quad+\sum_{p=0}^{2 p \leqq s-1}{ }_{s-1} C_{2 p}(y+4 p+1-s)^{s-j}
\end{aligned}
$$

One term on each side can be made to vanish by suitably choosing $x, y$. Thus we have a solution of

$$
\begin{aligned}
& a_{1}{ }^{n}+\cdots+a_{u}{ }^{n}=b_{1}{ }^{n}+\cdots+b_{u}{ }^{n}, u=2^{s-2}-1, \\
&(n=0, \cdots, s-1) .
\end{aligned}
$$

Similar devices give corresponding results for any $u \leqq 2^{s-2}$, and solutions containing parameters can also be given.

California Institute of Technology

\title{
A CORRECTION IN THE LIST OF PRIMES
}

BY D. N. LEHMER

My attention has been called by Andr. W. Mund of Basel, Switzerland, to a second error in the List of Primes published for me by the Carnegie Institution of Washington in 1914. The number 854651 listed in those tables is not a prime and should read 854647 . The error is due to an error hitherto undiscovered in Burckhardt's Tables of Divisors, in which an entry of 7 has slipped up one line. The error does not occur in my Factor Tables, and was introduced into the list from Burckhardt's tables, which were more convenient to read than the Carnegie tables.

All users of these tables should insert this correction. It is the second error to be discovered so far. (See this Bulletin, vol. 38 (1932), p. 902.)

The University of California 